\title{
LITERATURA, DISPARATE Y HUMOR EN MANICOMIO, DE FERNANDO FERNÁN-GÓMEZ
}

\author{
$\mathrm{M}^{\mathrm{a}}$ Teresa GARcíA-ABAD \\ CSIC, Madrid."
}

Esta especie de disparate escogido para este libro procede de la persuasión de que hay cosas disparatadas de un interés que se repite en la vida; cuadros de pesadilla que tienen la particularidad de proyectarse en nosotros en momentos lúcidos; grandes arañas que bajan del cielo claro de las tardes claras; situaciones que se resuelven sin resolverse, sólo quedándose pasmadas en la absurdidad; asuntos que realizaríamos y que nunca son realizados porque, como todo lo antedicho, son disparates, grandes disparates, visibles disparates; aunque los disparates excogitables, los disparates que se destacan con rotundidad de aciertos, son tratados injustamente porque la estética del acierto les es adversa, y si no los vence por su intensidad, los vence por su legalidad y por ser la admitida (Disparates, 443).

El humor ha sido siempre un elemento fundamental en la obra de Ramón, se vierte por todos y cada uno de los desmanes de la orgía verbal en que hace convivir a la palabra, y se traduce en una reflexión teórico crítica con su Teoría del disparate, pues el disparate es la forma más sincera de literatura. Disparates lleva por título uno de sus libros concebido

Este trabajo ha sido posible gracias a la financiación del Ministerio de Educación y Ciencia dentro del Programa Ramón y Cajal «Del papel a la pantalla: Literatura y cine» que se desarrolla en el CSIC de Madrid a cargo de $M^{a}$ Teresa García-Abad García. Se inscribe en el proyecto de investigación «Teoría y práctica de la adaptación cinematográfica de textos literarios en España (1950-1975)», dirigido por José Antonio Pérez Bowie. 
para Los Humoristas, una colección que da cabida a los más afamados cultivadores del género entonces, como Courteline, Arnols Bennet, René Benjamín, André Maurois o el español Julio Camba. Con la inclusión en esta empresa y colección, Ramón aceptaba ya definitivamente la etiqueta de «humorista», que le perseguía desde el principio pues el humor fue siempre un elemento fundamental de su obra. ${ }^{1}$

Manicomio es una película que cobra cuerpo como solución casi providencial a un disparate cuyos tentáculos se bifurcan en una extravagante historia, epitome de las carencias de una industria, un sistema cultural y una sociedad emergente de cenizas que apenas dejan atisbar los torpes movimientos de un intento de incorporación al cine de su tradición cultural más original y representativa.

Si el disparate se define como contrario a la estética del acierto, la película de Fernán-Gómez y Luis $\mathrm{M}^{\mathrm{a}}$ Delgado se puede vanagloriar del epíteto, por cuanto sobrevive y se asienta en los restos de varios naufragios de los que queda siempre incólume su sustrato literario, las aportaciones de la escritura de cuatro titanes de la literatura universal de entresiglos, pues el relato fílmico incorpora mucho más allá de la peripecia argumental del guión, claves imprescindibles para desentrañar el sentido último de las imágenes.

Con una modestia que excede lo justo, pero también con la rotundidad que invita a indagar en el significado de unas palabras que apuntan hacia la extraordinaria relevancia del estatuto de la literatura en el diseño de su obra fílmica, Fernando Fernán-Gómez ha afirmado: «quizás lo único de algún valor que tiene la película Manicomio le llegue de no ser original, sino adaptación de obras ajenas». ${ }^{2}$ Francisco Tomás Comes fue el encargado de seleccionar, de entre muchos cuentos que abordan el tema de la demencia, los que articulan la historia de Manicomio: «El sistema del doctor Alquitrán y el profesor Pluma», de Edgar Allan Poe, «La mona de imitación» de Ramón Gómez de la Serna, «Una equivocación» de Alexander I. Kuprin y «La idea» de Leonid Andreyev. El resultado, sin embargo, «no dejaba de ser un auténtico disparate en la España preburrotaxi», como así debieron entenderlo los juiciosos miembros del tribunal del Concurso Anual del Sindicato Nacional del Espectáculo, encargados de asegurarse su confinamiento al aristocrático limbo de lo inexistente.

1. Véase la introducción de Rafael Conte a Obras Completas V, pp.27-28.

2. Las adaptaciones literarias de obras ajenas representan la mayor parte de su labor como director cinematográfico y evidencian, en cualquier caso, el apego consciente a la dimensión literaria de su producción filmica. 
Pese a la tenacidad de Fernán-Gómez que consigue atraer la financiación imprescindible de Helenia Films, propiedad de Cayetano Torregrosa, y la ayuda de Eduardo Haro Tecglen, que facilitó un estreno previo, auspiciado por el diario Informaciones, ${ }^{3}$ la película no interesó ni al público ni a la crítica y «estaba claro que una de las razones, no la única, de su fracaso era lo que a nosotros - a mí, al colaborador en el guión y al codirector Luis María Delgado- más nos gustaba: su raíz literaria, su exceso de literatura. El público estaba de espaldas a un cine intelectualizado y tampoco la crítica se mostraba habitualmente a favor de un estilo que conceptuaba poco cinematográfico, defecto que solía atribuir al cine francés») (FernánGómez, 102-103). ${ }^{4}$

La fascinación de Fernán-Gómez por la literatura se desborda en las referencias constantes de sus memorias que afirman, más allá, su interés por lo insólito y su gusto por lo raro y lo heterodoxo: Arnold Zweig, Glaeser, Tcheng Chen, Heinrich Mann, Ann Shegers, Nathan Asch y Panait Istrati, «este último una revelación cuyo deslumbramiento no he olvidado (31). Sanz Villanueva se hace eco en el prólogo de La Puerta del Sol de una anécdota detallada por el escritor Enrique Azcoaga, en su diario íntimo del Café Gijón, en la que define un rasgo predominante de la personalidad creadora del director de Manicomio: «Ayer vino a la tertulia el gran lector Fernando Fernán-Gómez» $(\mathrm{X})$. Ros Berenguer recuerda las varias ocasiones en que el actor había declarado la importancia de la lectura de Gómez de la Serna, escritor del que se confiesa ferviente admirador has-

3. El festival artístico promovido por el diario Informaciones en beneficio de los damnificados por los temporales de Holanda en el Palacio de la Música constó de un programa concebido como un gran espectáculo compuesto por varias partes. En la primera, se exhibe la película precedida de una ingeniosa charla de Fernando Fernán-Gómez sobre el cine del momento y la ilustración dramática de una de las escenas de la película a cargo de los actores de su misma compañía teatral. Para finalizar, un gran fin de fiesta con la intervención de artistas de categoría internacional presentados por Boby Deglané entre los que se menciona a Gila, Peter Hurcos, Lady del Amo, Otto Sirgo, Peter Demon, Virginia Matos, Lita Norman, Rafael Cervera, Zori, Santos, Dolores Vargas...

4. «La película Aeropuerto, que en principio había de dirigir Luis María Delgado, se aplazó cuando ya estaban construidos algunos decorados, y decidimos rodar en ellos, dirigida por los dos, Manicomio, para lo cual aportaría yo mis escasos ahorros, el imprescindible Cayetano Torregrosa su crédito y unos cuantos, entre técnicos y actores, el resto por ir en cooperativa. Como el cine español acababa de salir de una crisis y ya había entrado en otra, grandes figuras estaban dispuestas a trabajar en condiciones miserables. No fue difícil, para una película hecha con tres perras gordas, conseguir un gran reparto: Antonio Vico, Vicente Parra, Julio Peña, Manuel Alexandre, Susana Canales, José María Lado, Elvira Quintillá, Carlos Díaz de Mendoza, Aurora de Alba, Fernán-Gómez... (FernánGómez, 1990: 102). Sobre las desafortunadas incidencias sufridas por el guión, el rodaje y el estreno de Manicomio véase Fernán-Gómez, pp.101-105 y Felipe Cabrerizo. 
ta el punto de proponerse encontrar una forma de trasladar su estilo, su visión del mundo, al teatro o al cine. Así Manicomio inicia una feliz trayectoria cinematográfica y constituye «el único momento en el que el cine español se ha acercado al espíritu de la obra de Ramón» (Cabrerizo, 14), porque transferir el ramonismo a la pantalla supone algo más que verter la peripecia de un breve sketch, «La mona de imitación»; se trata de acertar con el fondo de un disparate. ${ }^{5}$

La historia marco de Manicomio proviene del cuento de Edgar Allan Poe «El sistema del doctor Alquitrán y el profesor Pluma», cuyo protagonista decide desviarse de la ruta de un viaje por las provincias del Mediodía francés para visitar una casa de salud de la que ha oído hablar en París a médicos notables. La disciplina del centro se organiza conforme a una terapia experimental, el sistema de benignidad caracterizado por la inhibición de cualquier método represor con los enfermos: se evita el empleo de todo castigo; no se recurre a la reclusión sino en casos de gravedad extrema; los enfermos, vigilados secretamente, gozan en apariencia de una gran libertad, y pueden circular por la casa y por los jardines junto a las personas que están en sus cabales. El método no sólo no se niega al espontáneo comportamiento de los enfermos, sino que alienta sus caprichos, de modo que a los hombres que se creen pollos, por ejemplo, se les niega toda alimentación diferente a la que corresponde a las aves.

El sistema de benignidad ha dado como resultado el encerramiento de los médicos y del personal de la clínica por los locos que son ahora quienes suplantan sus papeles. «Los guardianes, en número de diez, habían sido súbitamente atacados, luego bien alquitranados, luego cuidadosamente emplumados, luego, por fin, secuestrados en los sótanos. Habían estado así encerrados más de un mes, y durante todo ese tiempo M. Maillard no solo les habia concedido generosamente el alquitrán y las plumas (lo cual constituía su sistema) sino también... algo de pan y agua en abundancia. Diariamente una bomba impelente les enviaba su ración de duchas...» (Poe, 203). De ahí el método del doctor Alquitrán y del profesor Pluma. La historia principal guiada por el hilo narrativo de su protagonista se bifurca en sendos relatos de locos: «La mona de imitación» de Ramón Gómez de

5. Ramón es también el modelo literario elegido por Luis Buñuel frente a Juan Ramón Jiménez. Sánchez Vidal da cuenta de un proyecto inacabado, la película de episodios de título Caprichos. Véase Mainer, p. 117. 
la Serna, «Una equivocación», de Alexander I. Kuprin y «La idea», de Leonidas Andreyev. ${ }^{6}$

Una paradoja que se vierte en la narración de la historia subrayada por el rótulo shakespeariano que acompaña a los créditos del comienzo, «Señor, danos una brizna de locura que nos libre de la necedad», y alerta al espectador sobre la inoperancia de acomodarse en un conflicto de lectura fácil e intrascendente, pese a la desenfadada música de Manuel Paradas que acompaña el inicio y una primera escena de clara raigambre cómico teatral.

Efectivamente, el comienzo de Manicomio ancla el discurso fílmico en lo cómico con una escena marco deudora de los gags más brillantes del genio humorístico. ${ }^{7}$ Un timbre de teléfono llama la atención sobre el objeto desde cuyo primer plano se abre a la presencia de Fernán-Gómez, quien atiende una conferencia con Guadalix de la Sierra. ${ }^{8}$ El propio desarrollo de la conversación telefónica permite los primeros despuntes de comicidad. La voz extasiada de Fernán-Gómez declama con fruición amorosa:

- «iAh, tu voz. Tu voz, Juanita!».

Inmediatamente el espectador reconoce la confusión; la voz que atipla el timbre de Carlos hasta el ridículo no corresponde a la de Juana, su novia, sino a un cruce de la telefonista que, sin duda, se lo habrá hecho saber para su ridículo. Restablecida la conversación, desaparece la arrobada impostación del enamorado e intuimos por sus respuestas que Juana, su novia, le invita a visitarla en el lugar en que se encuentra asegurándole

6. La mayoría de las referencias consultadas que reconstruyen las fuentes literarias de la película aluden a la historia de Andreyev con el título de «El médico loco». El protagonista de «La idea», título que recibe el cuento en la edición de obras completas de Rafael Cansinos Assens es, efectivamente, un doctor que se finge loco para poder cometer un asesinato con impunidad. No es improbable que el guión se sirviera asimismo de uno de los más famosos relatos del autor ruso, «Espectros», que se desarrolla en un manicomio.

7. Guillermo Linhoff pondera el acierto de este comienzo del conjunto de la película: «Partiendo de la base de que el gran actor del cine español Fernando Fernán Gómez quiso adentrarse en el campo de la dirección cinematográfica, y juzgando benévolamente este su primer ensayo, no nos parecería justo decir que ha fracasado en el empeño puesto que no está del todo mal Manicomio estrenada el lunes en varios cines a la vez. [...] El asunto tiene un arranque gracioso y prometedor y así llega hasta la mitad de la película con una anécdota salpicada de fino humorismo, basada en varios cuentos de conocidos autores, pero a partir de la citada mitad el film decae y no llega a tener una continuidad iniciada en su comienzo)?.

8. Conviene recordar la funcionalidad de los recursos sonoros en la retórica de la comedia de humor del momento para los inicios de acto que autores como Jardiel utilizan con profusión. Véase García-Abad, p. 64. 
que le gustará «este establecimiento» en el que se utiliza el sistema de benignidad.

Dicha escena funciona como marco del relato, ayuda a fijar el tono cómico del discurso y anticipa la planificación circular de la historia que vuelve sobre sí misma negándose a definir un desenlace imposible, «situaciones que se resuelven sin resolverse, sólo quedándose pasmadas en la absurdidad»s. ${ }^{9}$ Pero la envoltura de lo cómico intrascendente parece en definitiva querer enmascarar un planteamiento más eficaz, rodear de tules un trasfondo crítico que concilia la realidad con la fantasía, lo cómico y lo dramático, una hilaridad grave capaz de encerrar una visión prismática y esencial de lo humano donde el humor sólo sirve de disfraz para hacer más digeribles discursos que se arriesgan a perderse en el camino de la desidia, la pereza, la falta de compromiso o la más abierta censura. ${ }^{10}$ Recordemos que la prohibición del guión está estrechamente relacionada con la lectura en clave política de una historia que mostraba la España de 1952 en manos de unos locos y que concluía señalando que, en tal situación, un manicomio era el lugar idóneo para establecerse. Por ello tal vez, el tono jocoso en el que se desenvuelve el tema de la demencia de estos locos resulta a la Junta de Censura atentatorio contra la dignidad de un asunto, la locura, poco conveniente para ser tomado en broma y dar como resultado una comedia. ${ }^{11}$

9. La circularidad es una estructura idónea para los relatos que se detienen en las penumbras del pensamiento y de la vida, en las zonas no enteramente iluminadas de la conciencia, en todo lo que forma los aledaños del misterio. De ahí que los personajes de los cuentos y novelas de Andreyev suelen ser individuos tarados, anormales, semilocos o locos del todo, hombres atormentados como él mismo, que andan también buscando el sentido y la razón de la vida, el rayo de luz que los ilumine en medio de las nieblas que los envuelven. Todos se mueven en medio de sombras, como sonámbulos, y cuando creen ir hacia la luz y la libertad se hunden definitivamente en las sombras de la locura o la muerte, o vuelven a encontrarse de nuevo en el punto de partida, como el protagonista de esa fantasía onírica titulada Sueño o como el protagonista de Manicomio. Véase la introducción de Rafael Cansinos Assens a Andreyev, p. 22.

10. Francisco de Cossío se refería en un artículo de opinión publicado en $\mathrm{ABC}$ al día siguiente del estreno de Manicomio al sentido humano como cualidad inherente al humor: «Las dos condiciones para el buen humorista son, de una parte, la benevolencia, y de otra, el escepticismo. Estas cualidades colocan al que se ejercita en el humor en una situación ecléctica. Deforma la realidad que observa con un sentido humano, $y$, posiblemente, la historia de las costumbres, como mejor podemos comprenderla es a través de los humoristas» (3).

11. «El mismo Fernán-Gómez señala que 'esto en el país de Don Quijote, me parecía absurdo', pero se verá obligado a rescribir velozmente el guión infringiendo una larga serie de cortes al mismo. Finalmente, la censura terminará dando el placet a la nueva versión de Manicomio» (Cabrerizo, 19). La crítica se hizo eco asimismo con motivo del estreno de esta velada razón. Luis Gómez Mesa recordaba desde las páginas de Arriba la frecuencia con que el mundo de los locos había sido una variadí- 
Así, la visión más divertida del mundo le llega a Fernán-Gómez de un conocimiento cercano de los principales recursos del humor dramático desde el fino humorismo de Neville o Jardiel, a la astracanada y el retruécano, pero también de una prótesis de la visión literaria, de un ojo prismático, que permite acercarse a la realidad como los cubistas, «esa visión optimista con que se ve el mundo a través de una tallada cuenta de cristal que fue el mirífico monóculo que usamos en la infancia y que nos dio la visión más divertida del mundo». (Otras cosas, 892). ${ }^{12}$

O lo que es lo mismo, dicha profusión de signos aparentemente ingenuos suspenden al espectador en un fenómeno equivalente al efecto que Rafael Conte ha descrito para el lector de Ramón cuando afirma que éste pierde pie al entrar en contacto con su literatura:

Esto de perder pie cuando se entra en contacto con la literatura de Ramón es quizá uno de los primeros efectos, su consecuencia inicial y que resulta también a la postre principal. Lo que parece claro tiembla, lo más lógico cambia de sentido, toda retórica tiende a desaparecer, la literatura se desplaza no se sabe bien adónde, el texto se hace tan transparente que parece querer identificarse con su contenido, la progresión narrativa va por otros derroteros, se atomiza, el discurso se fragmenta y las palabras se humillan, se arrodillan hasta el punto de que cobran mayor importancia que nunca, pues al final no es que presenten sino que son las cosas que nombra (p.11).

Y este fenómeno de pérdida de solidez que parece presentarse como condición previa para seguir adelante se traslada de la letra a la imagen de la película Manicomio, pues en ella quedan confundidos los límites de la locura, y las fronteras de la cordura se precipitan durante la visita de Carlos (Fernán-Gómez), el cuerdo/loco, al hotelito/manicomio de Guadalix de la Sierra. El mismo desconcierto revestido de prudencia atenaza al personaje que desde el comienzo duda de la identidad de las personas que va encontrando a su paso como la señora de negro descrita en el relato de Poe: «Restringí, pues, mis observaciones a temas generales o a los que creía que no podían desagradar a una loca, ni siquiera excitarla. Respondió

sima e inextinguible fuente argumental que «puede ser visto en su patetismo de un modo truculento o deformado por la comicidad» pese a que los locos del mundo del cine no visitaban la pantalla con asiduidad y «sería un tanto muy favorable para el nuestro que hiciese una película de este asunto, claro que después de estudiarse minuciosamente el guión».

12. Son palabras de Ramón referentes a la sensibilidad fantástica de la vista de Juan Ramón Jiménez en El doctor Inverosímil. 
a todo lo que le dije de una manera perfectamente sensata, y sus observaciones personales estaban robustecidas por el más sólido buen sentido» (Poe, 188). El personaje guarda un parecido nada desdeñable con la mujer de uno de los cuentos de locos más conocidos de Andreyev, Espectros, en el que una muchacha bohemia canta el siguiente solo:

Ni debo amarte ni olvidarte puedo,

Y hondo dolor mi corazón destroza.

¡Contigo, el crimen, y sin ti, la muerte!

Lejos de ti, todo en mi vida es sombra.

Aunque maldigo mi pasión insana,

Me complazco en sus cuitas deliciosas.

$\mathrm{Ni}$ quiero amarte ni olvidarte puedo.

¡Malhaya el lazo!; pero ¿quién lo corta?

De esta suerte canta enajenada pese a lo cual su canto no parece una canción sino la realidad, y produce una viva impresión de realidad en las almas de todos aquellos que han conocido el amor: «Y mientras bebían percatábanse de que la vida sobria que habían llevado hasta entonces no era sino una mentira, un engaño; de que la verdadera vida, la real, estaba allí, en aquellos lindos ojos bajos, en aquellas exaltaciones del sentir y el pensar; en aquel vaso que acababa alguien de romper, derramando sobre el mantel un vino color de sangre» (Andreyev, 1951:28-29). ${ }^{13}$

El binomio lucidez/locura convive y se extiende a otras entidades bifrontes, realidad/ficción, realismo/fantasía, sueño/vigilia, cómico/trágico, cuerpo/alma, no menos implicadas en la reflexión en que se desenvuelve el arte y la vida. Personajes, escenarios y objetos pierden pie asimismo en la conciencia y la perspectiva de los hechos narrados. Pongamos un ejemplo suficientemente esclarecedor de este panmecanismo deformador referente a una más que probable tematización literaria del espacio urbano en la película.

El detenimiento de la cámara de Fernán-Gómez en una panorámica de las calles madrileñas acompañando el recorrido del automóvil que conduce a Carlos a las afueras de la cuidad para visitar a su novia subraya un interés que excede la mera ubicación espacial de la historia y se inscribe en una tradición de clara raigambre literaria. El protagonismo de lo urbano en la modernidad queda consagrado a lo largo del XIX en la literatura de Baude-

13. Del mismo modo, en un parlamento de Juana, la novia psiquiatra de Carlos, al final de la película se propone una inversión similar cuando se refiere a los enfermos enajenados como sus verdaderos compañeros, pondera su falta de hipocresía, su originalidad y su alegría de vivir. 
laire, Wordsworth, y Whitman, su epos inseparable de los paisajes, plazas y calles parisinos, londinenses o neoyorquinos. Está presente en la obra de Andreyev que culmina en Malditas fieras y La ciudad, en que el escritor refleja sus fobias neuróticas al espacio y su místico terror ante ese conglomerado social de la gran urbe, especie de Leviatán monstruoso que absorbe al individuo. Esta urbi fobia del escritor ruso forma parte de su gran espanto ante el misterio total de la Vida o de la Muerte -atendida la ambivalencia de ambos términos-, de su gran fobia cósmica.

De igual modo, la ciudad tematizada por la original perspectiva de Ramón deja su rastro en el conjunto de su obra. López Molina ha actualizado la relevancia de sus colaboraciones de La Esfera, gran parte de las cuales expresan la devoción del escritor por su entorno urbano; Madrid en primer plano, como no podía ser de otro modo, pero también Segovia, París y Nápoles vinculadas a la vida del autor. Y de entre toda esta galería de tertulias, cafés cantantes, personajes, costumbres, calles, plazas y jardines, un detenimiento muy especial en la Puerta del Sol, epicentro de madrileñismo y sujeto paciente de los «ojos reformadores» de los sucesivos responsables municipales. ${ }^{14}$ La ciudad corpórea y viva nutre su intimidad y se renueva respirando por las modernas oquedades que permiten a sus habitantes desplazarse por su interior: «Durante los primeros días del metro, y aun todavía, respira y transpira todo el fondo de Madrid por las narices y las bocas del Metropolitano; sobre todo por la naciente estación metropolitana de la Puerta del Sol, sale todo el olor del fondo de Madrid, y, sobre todo, de la Puerta del Sol, cuyas profundidades cuaternarias no respiraban hacía tantos siglos, ni echaban fuera la humedad de la fuente que hubo en ese sitio») (Variaciones, 628).

A su alrededor un crecimiento que se expande hasta las afueras donde se sitúan los merenderos de sus crónicas, reductos de felicidad que como el Botánico o el Rastro, suspenden la agitada vida de la metrópoli presta a ser recuperada con el crepúsculo. En las afueras, en Guadalix, se ubica el tranquilo hotelito donde tiene lugar la acción de la película de Fernán-Gómez, un espacio al que se accede no sin atravesar el inquietante muro de «Las afueras de la noche»:

Los sapos de canalillo se quejan, no como en los pueblos, sino como personas condenadas y tumefactas que llorasen y se quejasen de un dolor de muelas terrible, enjuagándose y aliviándose con su lamento.

14. Gómez de la Serna dedicó un libro a la plaza madrileña, Toda la historia de la Puerta del Sol. 
En las afueras se ve también que Madrid está cerrado por una valla de ladridos (no he querido decir de ladrillos).

Los caballos de la Guardia Civil pasan con un paso tranquilo, braceado, durísimo. Van dejando la huella de su herradura por donde pasan.

A lo lejos, en las afueras de Madrid, se oyen relojes de pueblo y hay una brisa marina» (OO.CC., 344).

La noche alberga un topos mítico de acabamiento. Así lo recoge Hernández-Catá en una novelita, Manicomio, cuyo prólogo indaga en los límites de lo lúcido, pues la muerte y la locura son dos hermanas engendradas por la noche primera del mundo para combatir con su oscuridad a los hijos gloriosos del día. ${ }^{15}$ La Muerte es segadora y trata por igual a todos los seres vivos; «la Locura tiene algo de sirena fúnebre, trabaja nada más con su soplo - parodia del soplo divino--, y puede compararse a un mal vidriero que inflase las imaginaciones hasta hacerlas estallar luego de infundirles formas arbitrarias» (Hernández-Catá, 589). ${ }^{16}$

Por su parte Dionisio Cañas ha señalado el estrecho vínculo que se establece entre el cuestionamiento de la identidad y la poesía que emerge o descansa en lo urbano, pues la ciudad agudiza el antagonismo entre lo íntimo (el Yo) y lo ajeno (los otros). La inmersión en la multitud desdibuja los contornos de la experiencia interior cuya realidad es recuperada en una reacción casi de supervivencia:

Por lo tanto, es importante para el poeta urbano delimitar su tiempo personal, y las condiciones de su Yo situado en la ciudad, con lo que esta situación conlleva: la angustia, la soledad, la alienación, el deseo, el amor, el miedo, la ansiedad, la culpa, y las reflexiones de orden ético sobre la existencia y la finitud. En cuanto al Yo público (en relación

15. La noche impone sus reglas que condenan a quienes las transgreden. Así, el que veia en la oscuridad, personaje ramoniano que como consecuencia de la mordedura de un gato en el codo tenía esa habilidad, fue volviéndose cada vez más misántropo: «Por ver en la oscuridad había visto antes de tiempo la verdad de la vida, la escena que la resume por entero. Por ver en la oscuridad había visto a los seres a quienes tenía más respeto aprovecharse de la oscuridad» (Disparates, 486).

16. «Michelet describió en perdurable página la aflicción del hombre al ver avanzar, hasta ennegrecerlo todo, la noche primera. Terror infinito, sin duda; mas su misma desmesurada grandeza lo desborda del cuenco vivo en donde caben los pesares humanos. Acaso el primer hombre ciego, el primer hombre manco, el primer hombre caído en un sueño del que era imposible reanimarle se ajustasen mejor a la concavidad sensitiva de los seres a quienes fue dado presenciar esos dramas en su tremenda ineditez. El primer loco hubo de producir, de seguro, una sensación superior en contenido de angustia a la producida por los dolores inexorables. Era, también, la primera noche, el primer eclipse dentro de un cráneo» (Hernández-Catá, 589). 
con los otros) tendrán que surgir el tiempo histórico, las multitudes, la deshumanización, la convivencia con los demás (Cañas, 10).

En Manicomio dicho vínculo aparece sintagmáticamente reforzado por el significado y la continuidad de las imágenes de la ciudad con el hilarante monólogo psicoanalítico de su protagonista que, asomado a la pantalla-ventana de su automóvil, relata con ansiedad patológica sus complejos y las paradojas que se hallan en la base de la confusión sentimental que padece; la razón última que determina la elección de su novia parece radicar en la resistencia mostrada por su familia hacia ella, a pesar de que es una chica «muy mona» y «muy decente», pues se dedica a una profesión muy extraña, la de médico psiquiatra: «Pero basta que mi familia se oponga para que a mí me guste más todavía». Los planes de la familia de Carlos habían dispuesto un conveniente matrimonio con su prima Mari Luz, una atractiva joven morena de ojos rasgados que se exhibe en una sugerente foto cuyo recuerdo desencadena en el personaje una resistencia irracional: «Prefiero a Juana Vélez, con manicomio y todo». Carlos sigue la estirpe del protagonista de la novela El Incongruente (1922), la preferida de Ramón, según aparece en La Sagrada Cripta de Pombo. La obra está construida sobre el nuevo «mal del siglo», a saber: la «incongruencia», encarnada en Gustavo, el personaje protagonista, del que leemos: «era un disolvente de todas las leyes de la vida, que se rompían, se enredaban, se quedaban aisladas y desanudadas cuando él se interponía entre ellas») (Serrano Asenjo, 166). Carlos aparece como el epítome del hombre fuera de lo normal que parece sin embargo ajeno a ello como un proyecto que no puede salir de su éxtasis de proyecto, en definitiva, como un disparate humano.

Toda la película bordea un planteamiento burlesco de la psiquiatría, del psicoanálisis, sus modas y sus excesos de ciencias que intentan poner razón a la locura. En el terreno del análisis críticoliterario algo de ello se vierte en la ironía que destila Ramón al abordar en su biografía sobre Poe ciertas perspectivas que se adentran a explorar los bosques interiores del escritor americano, como la encabezada por la princesa María Bonaparte que sentencia lo siguiente:

El relato de Pym es esencialmente la epopeya de la búsqueda de la leche en el cuerpo materno, simbolizado por los líquidos océanos, de acuerdo con la materia que domina para el niño de pecho el estadio oral, el relato de Legrand es la epopeya de la búsqueda de las heces de la madre, dentro de su cuerpo, simbolizado aquí por la sólida tierra, de acuerdo con la materia que domina para el niño, en el estado anal, fecal. Un preludio de esta segunda búsqueda estaba ya bosquejada en 
el relato de Pym, con las andanzas de Pym y Peters e los abismos de paredes negras con lentejuelas de metal que habíamos ya identificado como intestinos simbólicos») (18).

Sin pretender caer en semejantes desmanes, no parece descabellado pensar que el interior del automóvil según aparece subrayado por la imagen fílmica y a tenor de una infiuencia demostrable del epos simbólico ramoniano pueda albergar un espacio para la intimidad en su búsqueda de alma para las cosas:

El interior del automóvil tiene un alma reposada, fría, cauta. Es rápida, y como de caja registradora la reflexión o la meditación en el fondo del automóvil; pero es conducente, y los pequeños problemas se resuelven con una facilidad que es difícil preparar cuando se va a pie, porque en ese alma reservada del automóvil hay algo como un mecanismo de máquina calculadora, de sumar, de restar, de multiplicar, de dividir... En esa perspectiva que se ve por la ventanilla de delante está todo. En ese espacio que hay dentro del mismo coche se divisa todo con una separación que deja tener cierta egoísta impasibilidad... Hay en el automóvil una cosa de rincón -ese rincón que se buscan las arañas- que da un gran retraimiento al que va dentro. Así hay un momento en que le ven todos, y otro en que no le ve nadie» (628).

El disparate ramoniano participa de una tensión entre la lucidez y la insania, el humor y la seriedad. Para ello no vale la embriaguez sino la clarividencia de las mentes lúcidas, una lucidez, la que necesita el disparate, rayana de la locura que bebe en una tradición genuinamente española:

Este humorismo de mis disparates es el más español, el que informa el Buscón y el que informa también los aguafuertes de Goya. Ese humorismo central español, que no imita al humorismo inglés, ni esa forma distribuidora en partes del asunto y que saca un partido decente y sistemático de la gracia sin descabellarla, es el único humorismo que puede aspirar a quedar, porque ya ha pasado que solo lo que abruptamente fue de ese género es lo que ha ido quedando (446).

Locura y disparate cursan asociados a un proceso deformante de la experiencia y de sus formas como ya predijo la imaginación copiosa de Goya al establecer la monstruosidad derivada de las tinieblas del genio. Pese a su vínculo con la muerte, el loco no es un muerto, es, a lo sumo como señala Hernández-Catá, «un medio cadáver vertical, dinámico que permite la esperanza de verlo recobrarse. O es siquiera un ciego marchando entre tinieblas: es un vidente moviéndose entre imágenes para los demás invisibles. El ám- 
bito de su universo se ha modificado. La geometría de su inteligencia ya no es euclidiana: percibe dimensiones que sobrepasan a las tres percibidas por los sentidos. El loco cambia la brújula normal por otra que señala rumbos quiméricos. Vive ante un espejo donde su figura y los accidentes y atributos de su existir se reflejan en una profundidad al par irreal y visible») (589).

En Manicomio, los espejos presiden acciones y momentos clave donde se requiere la acentuación de dualidades subterráneas. La imagen de Mercedes, la mona de imitación, en el espejo del aparador del comedor conyugal repitiendo, «parece que lo que ha habido en ti siempre ha sido odio y no amor» es la carcajada trágica de la disolución violenta de una relación matrimonial, pero también de la creatividad, de lo original sepultado por la rutina, la repetición y la copia que conduce al asesinato «porque me hacía burla». Es la burla del espejo que de vez en cuando hace salir de su interior a alguien hecho a semejanza de otro: «De la gran repetición de los espejos brota después que se ha ido el reproducido, un ser como hijo de una fotografía de relieve, una fotografía extraña que le lanza un momento a la vida viable y engañosa. En los cafés, a veces, la gran clueca que es la realidad creacionista y milagrosa, fecunda una de esas huevas, una de esas imágenes del que ha estado mucho rato frente a los espejos, y el camarero, engañado, cree que es que ha vuelto el que parecía haberse ido, y un largo rato duda de su memoria que le había dado por ido» (Libro nuevo, 102).

De igual modo, los objetos y cuadros que adornan las paredes del manicomio de Guadalix parecen transmitir desde su silencio una sensibilidad anímica, su «pungencia telepática», los cuadros de pesadilla que tienen la particularidad de proyectarse en nosotros en momentos lúcidos: «El otro día, al entrar en la habitación, mi retrato tenía cara de haber llorado. Sobre mi mesa había un telegrama que solo encontré después de un rato de distracción. En el telegrama se me daba una triste noticia. El cuadro lo había sabido antes que yo. Y todo el kaleidoscopio cubista se había movido, y las lágrimas triangulares del cubismo pendían de mis mejillas amarillas) (Otras cosas, 1010)..$^{17}$

El disparate conlleva un proceso de acercamiento al mundo de los objetos y las cosas, un universo y una humanidad cosificados que parecen cap-

17. En el cuento Espectros, de Andreyev, cuya trama se desarrolla asimismo en un hospital psiquiátrico los cuadros son elementos relevantes en la utillería escenográfica de su director el Dr. Pomerantzev: «Adornaban las paredes tres cuadros que Pomerantzev había llevado, así como un gran retrato de su hijo, muerto de difteria hacía mucho tiempo; todo esto daba a la habitación un aspecto muy agradable. Pomerantzev estaba satisfechísimo de su cuarto, y se pasaba largos ratos contemplando los cuadros, de los que uno representaba una muchacha guardando unos patos; otro, un ángel bendiciendo la ciudad, y el tercero, un rapaz italiano» (12). 
turar el alma de los seres enajenados con los que conviven. Tal vez sea esta revelación una de las aportaciones más admirables de Ramón a la escritura del siglo XX. Así lo vio tempranamente Azorín cuando llama al inventor de la greguería «psicólogo de las cosas» y el mismo escritor cuando se presta a rescatar los fragmentos de un diario abortado reconstruye la siguiente imagen; la identidad pasada por el alambique de su genio: «Cuando se entrega uno a la imagen, fundiéndose en esa subjetiva objetividad que le es propia, ya no se puede hacer autobiografía. Se ha abandonado uno tanto a las cosas, que resulta que están las cosas sobre nuestro cadáver. Gracias a esto quizás no sintamos la muerte» (Variaciones, 673). La hipertrofia de este disparate se encarna en la hiperestésica, grotesco personaje cuya alma parece haber sido abducida por el empuje de los objetos hasta desplazar cualquier conato de humanidad:

Se tornó insensible a las personas, como tipos completos, y sólo encontraba en ellas un síntoma agudo.

Aquel pelmazo de Darío, que iba a verla para alegrarla con su sorna vulgar, no era para ella más que una insoportable sortija de sello que le imponía improbables blasones de nobleza, sobre los que se ladeaba una cimera con plumas que ya no se llevaban (La hiperestésica, 574).

Dicho protagonismo objetual se transfiere a la planificación visual de Manicomio en la intensidad que adquieren escenarios y cosas rescatados del arte para el arte, del teatro, la pintura o la literatura. Fernán-Gómez se nutre de este universo estético en sus fuentes expresivas que transfieren experiencias de unos medios a otros. ${ }^{18}$

Manicomio se alza, pues, entre una escenografía de disparate, oblicua, delicuescente, de retablo grotesco, de entraña literaria. La primera imagen regala al espectador con unas ventanas de ensueño, fundentes, de líneas quebradas cuyos barrotes son resaltados por las luces que proyectan sus sombras sobre la pantalla. Son barrotes de manicomio, rejas de loca, que a través de esta ruptura de la forma manifiestan su perfil humano y se distancian de las de la cárcel:

18. «El color de la posada de «los Rojos» oscilaba entre el blanco sucio y le gris. Mis conocimientos de las posadas o de las cadas campestres era sólo el de los decorados teatrales. Aquella posada, en la distribución de su zaguán, sí se parecía a lo que había visto, pero no en el color. El teatro de aquella época era burdo, ramplón, pero muy colorista por las decoraciones pintadas casi nunca corpóreas, y por el refuerzo de las luces de las diablas y las baterías. Tenía entonces el rectángulo del escenario una alegría, una magia luminosa que no tenían el cine en blanco y negro ni la vida real, aunque ingenuamente pensasen autores, directores y actores que su teatro era realista» (Fernán-Gómez, 1990, p.183). 
Así como los barrotes de la cárcel no tienen ese gesto de desesperación de la cabeza que intenta asomar por entre los barrotes, pues los que hay detrás de ellos son resignados, los de los manicomios tienen siempre un perfil humano como el hocico de un lobo en la jaula del parque. (Disparates, 528).

Pero el suceso más dramático e impresionante de una reja de loca lo he visto en el hotelito de las locas de pago, esas que son como máscaras provisionales de la locura. Incógnitas copartícipes en la mascarada de las locas, sufren el entredicho de locas hasta que paren su locura y se van. Muchas veces pasaba junto a ese hotelito blanco cuyas rejas son disimuladas rejas, todas con tipo de otra cosa, tipo modernista, tipo de adorno superfluo del balcón, de adorno para que no se caigan los niños. (Disparates, 529).

Los centros psiquiátricos suelen incluir un patio interior que en $\mathrm{Ma}$ nicomio encierra uno de los espacios más estilizados de la película compuesto por sobrias líneas rectas, rotas por un árbol solitario y una moderna escultura. La luminosidad de la estancia parece provenir de ese extravagante dispositivo ideado por Ramón para dotar de claridad a los patios interiores:

Por medio de un gran espejo empinado en lo alto del tejado de los patios interiores, y dirigido hacia el sol, yo lanzaría el sol hacia el fondo de esos patios para alegrar su vida. Esto sería sencillo y no muy costoso. Y sería seguro.

Yo he sorprendido esa posibilidad viendo cómo alegra a todo el patio ese rayo de sol que lanza su última ventana cuando su cristal, ladeado de cierta manera, recoge un destello y lo proyecta como un rayo verdadero.

Doremos de sol artificial a los patios interiores, y rescatemos las almas en pena que allí se pudren y tienen la cara llena de polvo y de oscuridad y en los ojos la telaraña de la miopía» (Disparates, 550-551). ${ }^{19}$

Los patios de los hospitales psiquiátricos necesitan al menos de un árbol, y el de este manicomio lo incorpora como un símbolo, porque «en

19. La luz atraviesa las modernas puertas diáfanas del mobiliario de Manicomio y se oponen a las puertas antiguas, recias, clavetadas. Se salva así a las estancias que pretenden encerrar de su angustia a cambio de la seguridad y de asumir un grado mayor de vulnerabilidad e indefensión: «Por estas puertas de cristales se ve toda la vida privada de la casa y se puede fisgar el secreto de su alma y hasta adivinar el sitio por donde es vulnerable» (Variaciones, 630). 
ellos acostumbran a apoyar su pesada cabeza los locos, sirviéndoles también eso para que algo de la electricidad de tormenta que hay en sus cabezas busque el fondo de la tierra a través de los árboles, y así se hace un poco el equilibrio de su alma» (Variaciones, 714). Es el árbol la materia conductora de la imaginación desatada de los locos que ha de morir en la tierra, ya que el mundo carece de árboles extraordinarios como los que propone la fantasía ramoniana, los que se podrían soñar en ese botánico digno de expectación: el árbol de los senos, el de los cascabeles, el de las campanillas y el gran cedro de los cencerros; los tres de la misma familia de los sonoráceos (Variaciones, 615).

Entre bromas y veras, la luna de miel de Amanda Blasco se torna en pesadilla cuando, víctima de la ficción que urde para intentar ahuyentar a los viajeros de su compartimiento y gozar de los ansiados primeros momentos de soledad tras su boda, es tomada por loca y conducida sin remisión al hospital psiquiátrico. Todo ello sucede en el interior de un tren con destino a Dinamarca que acoge escenas de acertada hilaridad, como la angustia de los recién casados, quienes no sólo han de reprimir sus deseos de abrazarse, sino que han de soportar la presencia de una estrafalaria señora sin problemas para conciliar un plácido sueño entre los movimientos violentos del vagón que la zarandean de un lado a otro y la hacen aparecer como un tancredo grotesco.

La dimensión trágica de los trenes como alegorías del viaje de la vida, de las ilusiones de exploración de otros territorios está presente en la literatura moderna que incorpora de forma entusiasta todo tipo de artilugios e inventos de progreso. Una ilusión que pronto se desvanece en la cosmovisión ramoniana y en lecturas de la película de Fernán-Gómez paralelas a esta paradoja que se detiene en la dimensión trágica de los trenes, de los viajes que no conducen a ninguna parte y se agotan en el quehacer de acabar con el hastío de los kilómetros de un abono, o en zafarse de la astilla siniestra del destino generada por su cruce: «Siempre temo a que se me clave la astilla del destino. Cuando se cruzan dos trenes en marcha con velocidad acrecentada hasta el máximum, siempre temo que de una portezuela, de la esquina de un vagón, de las mercancías que van apiladas sobre las plataformas, surja la astilla fatal con violencia de faca tirada con fuerza por el que la ha empalmado, por el mismo destino, tan artero en las cuchilladas que dispara. Siempre me he replegado dentro del vagón al ver 
pasar el otro tren, procurando evitar la astilla de la Providencia, la puñalada del cruce» (Disparates, 603-4). ${ }^{20}$

En efecto, entre el atrezzo abigarrado de los despachos de los psiquiatras -paredes adornadas con cuadros abstractos que han perdido el equilibrio y cuelgan desviados hacia alguno de sus lados, pieles de animales decapitados cuyo lugar es ocupado por máscaras africanas-, llama la atención las cortinas a rayas que denuncian de manera muy evidente este deseo de subrayar el caos geométrico que se ha apoderado del espacio. Si como leemos en Ramón, además, esas cortinas rayadas aparecen como emblema del héroe doméstico, la perturbación que encierran de la vida normal, de los seres normales, de sus símbolos más definidores, se extrema y nos obliga a pensar que entre los locos de Manicomio no abunda tanto la especie de «loco de remate», sino esa otra que deriva de la contemplación de la realidad doméstica y de sus paradojas más hirientes:

Había dejado dicho: «Cuando yo me muera que me envuelvan en una cortina de mi despacho, en una de esas cortinas a rayas largas, amarillas, rojas, azules y negras, que han resultado para mí las banderas de la patria en la insistencia de mi trabajo.

En efecto, al buen hombre doméstico, siempre metido en su despacho y mirando a través de sus cristales el cuadro dudoso de la vida, al héroe de esa heroicidad íntima y escéptica, lo envolvimos en uno de los paños de las cortinas de su despacho como se envuelve en la bandera a los militares que mueren en campaña» (Disparates, 588).

Los desfigurados parámetros que envuelven el relato se extasían en una medición íntima del tiempo. La omnipresencia de relojes de todas las variedades conocidas, su uso repetido y extravagante, la relevancia de los planos del objetivo de Delgado y nuevamente su consideración en la escritura ramoniana ayudan a entender su sentido en el discurso. Son los sempiternos relojes de pared que miden la losa del tiempo y el tedio de los comedores en los que la vida se manifiesta en el rutinario tic-tac de su péndulo; el excéntrico reloj despertador que saca de su bolso la molesta viajera a Dinamarca, o las múltiples llamadas de las que consta la historia del Dr. Posada, cuya acción tiene lugar siempre a las ocho en punto, hora

20. Las estaciones comparten dicha visión fantasmagórica que Ramón advierte también en la literatura de Poe: «Una estación es lo más lleno de fantasmas y lo más tétrico que hay. Se pasean por su andén muchos seres que quisieran tomar el tren, ansiosos, invisibles y misteriosos viajeros. Hay una inquietud en la estación que no es de los que están, sino de los otros, de los que estuvieron, de los que estarían, de los que se despidieron, de los que quisieran irse, de los que quisieran volver». 
que nos recuerdan los relojes de mesa, de pared, o el tic-tac cristalino de los relojes de bolsillo...

El reloj de bolsillo que a veces coloco sobre la mesa porque resulta que los relojes de pared no acaban de señalar la hora íntima y precisa, ha tenido hoy un ruidillo que había perdido hacía tiempo, un ruidillo agudo, pertinaz, sutil, volviéndose el tic-tac metálico un cristalino tic-tac, como si fuesen de fino cristal las ruedas y los dos puntos muertos en que martillea el volante sonasen dentro de una copa de Bohemia.

Hacía mucho tiempo que no oía ese tono del reloj, quizá desde aquel principio de curso en que me dejaron interno en un colegio con un reloj de bolsillo por toda compañía íntima. Desde entonces no había tenido un tono tan entrañable el reloj.

¿Qué me irá a pasar? ¿Qué emoción profunda me anuncia? ¿Me iré a morir?

Desde aquel angustioso momento del internado, digno de dedicárselo a Nuestra Señora de las Angustias, y en el que el reloj hizo el pobre todo lo que pudo por entretenerme, no he vuelto a oír un tic-tac así» (Otras cosas, 956).

La locura se desata en el desenlace de la historia, un festín alrededor del cual se congregan los ilustres comensales dispuestos a dar cuenta de un menú compuesto por ternera a la Sainte-Menáhoula y coliflores con salsa aterciopelada. La delicadísima ternera es transportada por tres robustos criados a la mesa en un enorme plato, «que más bien parecía un barco», una ternera asada entera, apoyada en sus rodillas con una manzana entre los dientes, según la moda usada en Inglaterra para servir una liebre. Ante su sorpresa, Carlos busca con su mirada una alternativa y se detiene en algo que parece ser conejo casero, a lo que el anfitrión inquiere a los camareros que sirvan ese «conejo al gato». Los comensales, veinticinco a treinta, son en apariencia personas de buena sociedad aunque sus trajes denuncien una ostentación extravagante, todos ellos, dedicados a contar historias de locos: el que se creía tetera de fabricación inglesa y se cuidaba de limpiarse todas las mañanas con una gamuza; el asno que no quería comer más que cardos y daba coces (indica cómo); el que se cree un queso y se pasea con un cuchillo en la mano invitando a sus amigos a cortar, para saborearlo, un pedazo de su muslo; el que se figuraba ser una botella de champaña y hablaba siempre con un pau... pau... y un pschi... i... i... Algunos también reclaman manías inspiradas en el sentido común como 
la anciana que había descubierto, tras madura reflexión, que había sido transformada por un singular accidente en gallo. ${ }^{21}$

Entre el desbordamiento festivo del desenlace filmico se trasluce un sustrato construido de las lecturas que inspiran la película y perfilan jocosas locuras para la risa y también psicologías deformadas por el medio. Los locos de Andreyev, como el doctor Kerchentsev, el psiquiatra asesino de La idea, han sido entendidos en el contexto sociopolítico de la época como exponentes de una histeria difusa que, como la tuberculosis, apenas respetaba a nadie en Rusia, debido a las condiciones anormales en que por efecto del régimen politicosocial vive allí entonces todo el mundo. ${ }^{22}$ Afecciones y circunstancias que acentúan un complejo de inferioridad que debía ser endémico en aquella Rusia autocrática y rígidamente jerarquizada:

Desde luego y como era de esperar, atendidas las circunstancias políticosociales de la Rusia de su época, los casos que más abundan en ese elenco son los del complejo de inferioridad compensado por la tendencia egolátrica. El afán de distinguirse en esa Rusia, donde solo el privilegio asegura un mínimo de consideración al individuo y donde todos, según la gráfica expresión dostoyevskiana, están o se sienten humillados y ofendidos, suele ser el punto inicial de esa psicosis. Esos burócratas modestos, perdidos en el escalafón; esos humildes curas de aldea ahogados en un ambiente de poblado inculto, sienten el afán de distinguirse, de llamar la atención, y caen en extravagancias, a veces fatales (Cansinos-Assens, 26).

Así, el marido asesino de «La mona de imitación» recuerda que antes de su locura era un sujeto vulgar que trabajaba en una modesta oficina, pasaba un rato en la taberna y de camino a casa donde le espera paciente su mujer a la hora de la comida se detenía a comprar el periódico, en $\mathrm{Ma}$ nicomio, el diario Pueblo.

Poe y Ramón comparten una visión del mundo y la literatura fijada por este último en su genial biografía del escritor americano. Su llegada

21. «Muchas señoras que no tenían menos de setenta años, estaban adornadas con profusión de cadenas, dijes, sortijas, brazaletes y pendientes, todo un surtido de bisutería, y mostraban sus senos y sus brazos ofensivamente desnudos. Noté igualmente que muy pocos de estos trajes estaban bien cortados o, al menos, muy pocos se adaptaban a las personas que los llevaban. Mirando a mi alrededor, descubría a la interesante jovencita a quien M. Mailland me había presentado en la sala de visitas; pero mi sorpresa fue enorme al verla emperifollada con una enorme falda de volantes, con zapatos de tacón alto y un gorrito de encaje de Bruselas, demasiado grande para ella, tanto que daba a su figura una ridícula apariencia de pequeñez (Poe, 191).

22. Véase la introducción a la obra completa de Cansinos-Assens, p. 23. 
a las librerías españolas y su entusiasta acogida en las páginas de las revistas encargadas de hacer crítica literaria en el mismo mes y año en que se repone Manicomio en cuatro salas de Madrid son el testimonio vivo de la desigual recepción de su figura en ambos medios. Entre otros, José $\mathrm{M}^{\mathrm{a}}$ de Sagarra indagaba en Destino sobre las causas posibles de estas enigmáticas incomprensiones para acabar concluyendo lo siguiente: ${ }^{23}$ «Este Poe de Ramón no es un Poe para uso de lo que Ramón llama la zoocracia, porque, claro está, la zoocracia nunca podrá comprender a Poe ni podrá interesarse por él. Tampoco es un libro a nivel de toda la cantidad de lógica que pueda aceptar la sensibilidad de los lectores de biografías. Hoy día esta clase de libros se elaboran con lupa y se procura aportar con su contenido una gran dosis de realidad y de documento directo. Se llega a la síntesis del personaje por el camino del mosaico, de la trituración, de la discriminación y del chismorreo. En este aspecto se han logrado biografías preciosas y de sumo valor, pero en la mayoría de los casos exangües, sin color y sin alma».

Una zoocracia siempre dispuesta a sofocar por acción o preterición las dosis de realidad que se colaban entre el tapiz cómico de Manicomio, una realidad en guardia contra las ficciones escritas por el poder para dominar la vida de sus súbditos o un lamentable ejemplo de disparate excogitable, el que se destaca con rotundidad de acierto, y es tratado injustamente porque la estética del acierto le es adversa. ${ }^{24}$

23. Véase también el artículo de Antonio Vilanova.

24. Sobre las relaciones entre cine, literatura y poder en los años 40 , véase Pérez Bowie. 


\section{BIBLIOGRAFÍA}

AndReyev, Leonidas, Los Espectros, Madrid, Espasa-Calpe, 1951. , OO.CC., Madrid, Aguilar, 1969.

CABRERIzo, Felipe, «Manicomio, el extraño viaje de ramón a Cinelandia», Boletín Ramón, $\mathrm{n}^{\circ} 9$ (2004), pp.14-23.

CAnsinos-Assens, Rafael, Pról.. a Andreyev, pp.10-71.

Cañas, Dionisio, El poeta y la ciudad. Nueva York y los escritores hispanos, Madrid, Cátedra, 1994.

Cossio, Francisco de, «Humorismo y Humoristas», $A B C, 10-\mathrm{III}-1953$, p.3. DONALD, «La película Manicomio de Fernando Fernán-Gómez en los cines

Panorama, Proyecciones, Progreso y Tívoli», $A B C, 27-\mathrm{I}-1954$, p. 31 . , «Festival de Informaciones, en el Palacio de la Música», ABC, 10-III-1953, p.38.

Ferná-Gómez, Fernando, El tiempo amarillo. Memorias 1943-1987, Madrid, Debate, 1990.

, La Puerta del Sol, Madrid, Espasa Calpe, 2000.

Garcia-Abad García, Ma Teresa, Intermedios. Estudios sobre literatura, teatro y cine, Madrid, Fundamentos, 2005.

Gómez de la Serna, Ramón, Edgar Poe, el genio de América, Buenos Aires Losada, 1953.

, OO.CC. XI. Novelismo III. Novelas cortas y cuentos para niños (1921-1932), Ed. de Ioana Zlotescu, Barcelona, Círculo de Lectores/Galaxia Guetenberg, 1999.

, OO.CC. V. Ramonismo III. Libro nuevo. Disparates. Variaciones. El alba. Ed. de Ioana Zlotescu, Barcelona, Círculo de Lectores/Galaxia Guetenberg, 1999.

, Toda la historia de la Puerta del Sol y otras muchas cosas, Madrid, Talleres Gráficos de La Tribuna, s.a.

Gómez Mesa, Luis, «Cine. Panorama, Progreso, Proyecciones y Tívoli: Manicomio», Arriba, 26-I-1954, p.14.

, «Cine. Palacio de la Música: Manicomio, en el festival de Informaciones》, Arriba, 10-III-1953, p.15.

Hernández-CatÁ, A, Manicomio, Revista Literaria. Novelas y Cuentos, ${ }^{\circ}$ 231, 4-VI-1933.

LinHoff, Guillermo, «Manicomio, en Proyecciones, Progreso, Panorama y Tívoli», El Alcázar, 27-I-1954, p.4.

López CoBo, Azucena, «Los objetos en la novela de Ramón Gómez de la Serna. En busca del tiempo detenido y del lector partícipe», Boletín Ramón, nº 9 (2004), pp.3-13. 
Mainer, José-Carlos, «El espejo inquietante: Ramón y el cine». En Peña Ardid (Coord.), 1999, pp.109-134.

PeÑA-Ardid, Carmen (Coord.), Encuentros sobre Literatura y Cine, Zaragoza, Instituto de Estudios Turolenses, 1999.

Pérez Bowie, José Antonio, Cine, Literatura y Poder. La adaptación cinematográfica durante el primer franquismo (1939-1950), Salamanca, Gráficas Cervantes, 2004.

Poe, Edgar Allan, OO.CC., Compilación y prólogo de Armando Bazán, Buenos Aires, Claridad, 1969.

Ros Berenguer, Cristina, «Adaptaciones literarias del realizador F. FernánGómez: de Manicomio (1953) a Cómo casarse en siete días (1969)». En Juan A. Ríos Carratalá y John D. Sanderson (Eds.), pp.39-51.

Ríos Carratalá, Juan Antonio y SANDERSON, John D. (Eds.), Relaciones entre el cine y la literatura. El teatro en el cine, Alicante, Universidad, 1999.

Sagarra, José Ma de, «Antepalco. Poe y Ramón», Destino, 30-I-1954, nº 860, p. 6 .

Serrano Asenjo, José Enrique, Ramón y el arte de matar. (El crimen en las novelas de Gómez de la Serna), Granada, Caja General de Ahorros, 1992.

Serrano VÁzquez, $\mathrm{M}^{\mathrm{a}}$ del Carmen, El humor en las greguerias de Ramón. Recursos lingüísticos, Valladolid, Universidad de Valladolid, 1991.

VILANOVA, Antonio, «La letra y el espíritu. Una nueva efigie de Ramón», Destino, 10-IV-1954, n 870, p. 24. 